\title{
REVISIÓN/REVIEW
}

\section{LOS FESTIVALES DE CINE COMO ELEMENTO POTENCIADOR DE DESTINOS TURÍSTICOS. EL CASO DE SAN SEBASTIÁN}

\author{
Noelia Araújo Vila1: Universidade de Vigo. España. \\ naraujo@uvigo.es
}

Trinidad Domínguez Vila: Universidade de Vigo. España. trinidad@uvigo.es

\section{RESUMEN}

En este trabajo se presenta una investigación del campo del turismo cultural, concretamente de los festivales de cine y su incidencia como elementos que potencian e incrementan el número de turistas durante su celebración, y mejoran la imagen de la ciudad como destino turístico, tanto a nivel nacional como internacional, gracias a la cobertura y difusión de los medios de comunicación desplazados al evento. Por ello, se realizó un estudio de los festivales de mayor relevancia y posteriormente se analizaron las páginas web oficiales de dichos festivales y las de turismo de las ciudades sede del evento. La comparativa entre ellas dio como resultado el estudio en profundidad del festival de cine San Sebastián como elemento de mejora de la actividad turística y componente fundamental en la creación de imagen de destino de la ciudad, tanto a nivel nacional como internacional, como prueba el hecho de que será la próxima capital cultural de Europa en 2016.

PALABRAS CLAVE: Turismo cultural - Festival de cine - Destino turístico - Imagen del destino - San Sebastián

\footnotetext{
1 Autor correspondiente:

Noelia Araújo Vila: Profesora invitada e investigadora del Departamento de Organización de Empresas e Marketing de la Facultade de C.C. Empresariais e Turismo de la Universidade de Vigo. España.

Correo: naraujo@uvigo.es
} 


\title{
FILM FESTIVALS AS TOURIST DESTINATIONS DEVELOPERS. THE CASE OF SAN SEBASTIÁN
}

\begin{abstract}
This paper presents a study about cultural tourism, specifically the film festivals. It tries to analyze the incidence of this type of festivals like elements that improve and increase the number of tourists in these dates, and improve the image of the city like tourist destination, so much to national level like international because the coverage and diffusion of the mass media displaced to the event. For it, a study of the festivals of greater importance is realized and later the official web pages of the festivals and the ones of tourism of the cities calm of the event were analyzed. The comparative between them gave a result the study in depth of the film festival San Sebastian like element of improvement of the tourist activity and fundamental component in the creation of image of destination of the city.
\end{abstract}

KEY WORDS: Cultural tourism - Film festival - Touristic destination - Image of destination - San Sebastian

\section{INTRODUCCIÓN}

Hasta finales del pasado siglo, en España, el modelo turístico por excelencia era sol y playa; mas en los últimos años el turista ha incrementado su demanda, emergiendo nuevas necesidades para las que este modelo turístico no era suficiente. El actual turista demanda experiencias y sensaciones, siendo necesario para su satisfacción una mayor y novedosa oferta turística. Emergen así nuevos tipos o variantes de los ya existentes, siendo dentro del turismo cultural donde han proliferado mayor número de productos y paquetes turísticos.

El turismo cultural abarca un amplio campo y conjunto de actividades, vinculadas con el folclore, lo artístico, religioso, industrial o lúdico-festivo. Se trata de un concepto muy extenso, que incluye toda actividad que pretenda responder a la necesidad de enriquecimiento cultural, educación, novedad y socialización.

Como respuesta a dicha necesidad y como parte de los eventos lúdico-festivos, emerge con fuerza el turismo vinculado a la celebración de festivales de cine. El festival de cine se convierte en el verdadero atractivo y reclamo para el consumidor, y los recursos turísticos del destino, en la perfecta oferta complementaria que da lugar a un producto lúdico-turístico de lo más completo y atrayente.

Por ello, el presente artículo parte de una revisión teórica del turismo cultural y tipologías que abarca, para finalmente centrarse en los festivales de cine del panorama español y su vinculación con el sector turístico. Como caso de estudio se analiza el Festival Internacional de Cine de San Sebastián, un referente dentro y fuera del país, a 
través de un análisis de contenido de su página web oficial y comparación con otros festivales de gran repercusión y también pertenecientes a la categoría A según la FIAPF (International Federation of Film Producers Associations).

\section{UNA NUEVA VISIÓN DEL TURISMO: EL TURISMO CULTURAL}

El fenómeno del turismo cultural existe antes de que el turismo se constituyese como un sector económico, aunque hace relativamente poco tiempo que se reconoce específicamente dentro de la actividad turística y de la promoción cultural. Por la propia evolución del mercado, la industria turística busca alternativas al modelo anterior basado en sol y playa, intentando dar respuesta a una demanda más exigente, segmentada y cambiante para poder realizar una oferta cultural más dinámica y competitiva así como proporcionar alternativas a través de nuevas experiencias y la diversificación como un elemento de reclamo principal o también complementario (Bonet, 2003).

Es importante tener en cuenta que el turismo cultural en sí mismo no garantiza un desarrollo económico estable, aunque puede actuar como factor estratégico para la economía local a través de la generación de rentas de empleo, pudiendo reducir la estacionalidad. Pero no se debe obviar que el turismo puede ser un arma de doble filo, siendo el responsable de la mercantilización y falseamiento de diversas manifestaciones culturales tradicionales o del propio entorno natural, rompiendo la utopía de la búsqueda de sentido, belleza y autenticidad de las sociedades occidentales contemporáneas (Richards, 2004).

Tras tal inmersión en el turismo cultural, se intuye a grandes rasgos lo que éste abarca, pero ¿qué se entiende por turismo cultural? Dentro del turismo cultural o del grupo turismo cultural e histórico, a día de hoy se encuadra lo que va desde lo pintoresco o restos de una vida en extinción a las rutas de ruinas, monumentos y museos (Santana, 2003: 3). Según las indicaciones de la OMT (1985), se define como "un movimiento de personas esencialmente por una motivación cultural, tal como viaje de estudios, festivales $\mathrm{u}$ otros eventos culturales, visitas a monumentos, lugares, folklore, arte o peregrinación". Según Richard y Bonink (1995), es "el movimiento de personas de su lugar normal de residencia en busca de atracciones culturales con la intención de reunir nueva información y experiencias que satisfagan sus necesidades culturales". En definitiva, estamos ante un concepto muy amplio y según a que se emplee en concreto nos encontramos con cifras que varían sustancialmente. Así, algunos investigadores afirman que el turismo cultural representa el 70\% del mercado global, la OMT estima sobre el 37\% del turismo mundial y Association for Tourism and Leisure Education (ATLAS), que sólo incluye a los que viajan por motivos específicamente culturales, estima que el turismo cultural engloba entre el 5\% y el 8\% del total del mercado (Richards, 2004).

Dada la fina línea que separa las tipologías turísticas, a veces se hace difícil distinguirlo del turismo recreativo, pudiendo convertirse en un complemento del mismo. En definitiva, al referirnos a habituales turismos como el artístico, religioso, 
industrial o lúdico-festivo, estamos haciendo referencia a un campo mayor que es el turismo cultural (Tabla 1).

Tabla 1. Tipologías de Turismo Cultural.

\begin{tabular}{|l|l|}
\hline Turismo & - Histórico/artístico \\
Cultural & - Histórico artístico \\
& * De arquitectura popular \\
& * De exposiciones \\
& * Étnico \\
& - Étnico folklore \\
& * Costumbres y tradiciones \\
& - Religioso \\
& - De formación \\
& - De acontecimientos singulares \\
& - Lúdico-festivo \\
& - Literario y cinematográfico \\
& - Gastronómico \\
& - Industrial \\
& - De compras o shoping
\end{tabular}

Fuente: Elaboración propia a partir de Acerenza (1991)

Este campo contempla una serie de actividades que buscan satisfacer la curiosidad del turista a través del encuentro de éste con culturas exóticas, culturas distantes, arte y folclore $u$ observación de ciertos edificios, pueblos o monumentos que por su historia presentan cierto interés, desencadenando una serie de sensaciones intelectuales, emocionales y psicológicas en el individuo (Stebbins, 1996, p. 948). La motivación de este tipo de turismo es multidimensional (Villa, 2001), por lo que el turista no pretende experimentar una sola experiencia mientras lo practica.

El elemento influenciador en la oferta de esta tipología, en cuanto a forma, ubicación y producción, va a ser quien la consuma (Richards, 1996, p. 262), convirtiéndose el turista en quien consume rasgos culturales a la vez que reconstruye, produce y mantiene culturas (Santana, 2003, p. 5). El proceso que se sigue para ello, es la transformación de un elemento o rasgo cultural en recurso, de ahí en producto, a continuación en experiencia y finalmente se obtiene un resultado, que marcará el nivel de satisfacción del turista cultural (Craik, 1197, p. 113). Todo el proceso se culmina con la compañía de los factores del disfrute y la aventura, con imágenes y sueños que consiguen la integración del turista con un medio multitudinario que finalmente siente como propio y auténtico. Por ello toda cultura o hecho entendido como escaso, extraño y sobre todo atractivo a la mirada, es el elemento más buscado para ser transformado en recurso y posteriormente en producto, reorientándose y adaptándose al post-turista, dando lugar finalmente a un resultado en concreto, una experiencia única e inolvidable (Markwell, 2001). 


\section{E1 TURISMO CULTURAL DE FESTIVALES Y EVENTOS}

Como se acaba de ver, el turismo cultural ya no se entiende como un fenómeno aislado y minoritario, sino como una oferta turística más con sus correspondientes productos complementarios y periféricos. El problema deriva de lo que se entienda por cultura, ya que desde una perspectiva amplia existe turismo cultural en la gran mayoría de los productos turísticos ofertados por el sector, ya que todo destino ofrece en un grado u otro alguna oferta cultural, por lo que es necesario acotar el análisis del turismo cultural a la demanda y oferta relacionada con turismo patrimonial (visita a museos, monumentos, edificios civiles, militares, industriales o religiosos, centros históricos o parques arqueológicos y naturales) y eventos relacionados con la cultura tradicional (fiestas patronales, encuentros folclóricos, ferias de arte, discos o libros, etc.) donde se agrupan los festivales de cine (Bonet, 2003), objeto de estudio del presente artículo.

El turismo vinculado a los festivales, perteneciente al segundo bloque citado de turismo cultural, está en auge en nuestro país, por una parte motivado por el incremento considerable de festivales -actualmente más de 400-, y por otra, por tratarse de un tipo de turismo susceptible de complementarse con otras tipologías o modelos turísticos tradicionales de España, como el ya mencionado sol y playa, renovándose así este tradicional modelo hacia nuevos segmentos de mercado. Estamos por tanto ante un tipo de turismo apropiado para desarrollar nuevos productos adecuados a la demanda de nuevos consumidores (Gonzalo, 2006). A ello se añade el componente experiencial o el contacto con la población local, características también altamente valoradas por el turista actual (García y Alburqueque, 2003, p. 100-101).

Desde el punto de vista de este nuevo turista, se entiende que estamos ante un consumidor que busca enriquecimiento cultural, educación, novedad y socialización, lo que según Crompton y McKay (1997) se traduce en una serie de motivaciones que llevan al consumo de turismo de festivales:

- Novedad: deseo de buscar nuevas y diferentes experiencias a través de viajes motivados por el deseo de experimentar emociones y aventuras altamente ligado con el concepto de turismo experiencial- (Lee y Crompton, 1992).

- Socialización: necesidad de interactuar con un grupo.

- Prestigio/status: deseo de ocupar una alta posición ante los ojos de la gente que nos rodea.

- Descanso y relax: evadirse mental y físicamente de la rutina.

- Valores educacionales/enriquecimiento intelectual: deseo de ampliar los conocimientos intelectuales.

- Mejorar el parentesco y relaciones: deseo de mejorar las relaciones familiares.

- Regresión: deseo de participar en experiencias/comportamientos que nos recuerdan a la etapa de adolescente o niño. 
Tras conocer cuáles son los estímulos que incitan al turista a consumir este tipo de turismo cultural, también son relevantes los cambios sociales que se han producido dando lugar a ventajas tanto en la oferta como la demanda (Gonzalo, 2006), potenciándose así este tipo de celebraciones:

- Tiempo disponible: se ha producido un incremento tanto en nivel de ingresos como de tiempo disponible para el ocio (fruto de la reducción de la jornada laboral). Ambos factores favorecen el consumo de turismo cultural en general, en una sociedad donde el enriquecimiento espiritual ha ganado importancia (Inglehart, 1989). Además, los festivales han sabido adaptarse a las nuevas tendencias del consumidor, ofertando infraestructuras y facilidades que permitan al consumidor compaginar diversos espectáculos con actividades complementarias.

- Costes de transacción: las agencias de viajes o incluso páginas webs de los propios festivales, ofrecen paquetes que incluyen las entradas al festival o bonos para varios días y varios espectáculos, reduciéndose así los costes asociados al viaje y estancia en el destino turístico.

- Excepcionalidad y notoriedad: la concentración de gran número de actividades durante un festival, consigue crear una campaña comunicativa del destino turístico de gran repercusión, lo cual no se podría conseguir de otro modo.

- La "aversión" a la cultura: los festivales consiguen atraer a un tipo de turista que habitualmente no es seguidor de la cultura (museo, ballet o teatro), ampliándose así el número de usuarios y potenciales turistas.

- La "Ley de Baumol": los eventos culturales normalmente tienen un coste laboral unitario muy elevado, ya que se siguen necesitando tantos trabajadores como hace años. Es una industria en la que no se ha podido reducir el personal e incrementar la productividad, dadas sus características. Sin embargo, los festivales, al ser eventos puntuales con una temporalidad determinada, contratan a la mayor parte del personal en ese periodo en concreto, reduciéndose así el coste.

Aparte de dichas ventajas, no se debe obviar que los festivales deben despertar siempre expectación y novedad, de tal manera que supongan para el turista un atractivo que los haga desplazarse al destino turístico.

\section{El TURISMO DE FESTIVALES DE CINE EN ESPAÑA}

Hasta el momento, se ha hablado de festivales de un modo genérico, pudiendo incluirse en dicho campo los de teatro, cine, danza o gastronomía. A continuación, la presente investigación se centrará en tan sólo uno de ellos, del que actualmente se ofertan más de 70 eventos en España, teniendo algunos más de 50 años de antigüedad: los festivales de cine.

Dentro de la oferta de festivales de cine, existen diversas categorías, lo cual depende del número de películas participantes, la relevancia de sus participantes y la cantidad 
de países que determina su grado de internacionalización (Reinstein, 2009). La categoría más alta es la denominada A, a la que en 2011 pertenecen tan sólo 14 festivales (Tabla 2) según la FIAPF (International Federation of Film Producers Associations).

Tabla 2. Festivales de categoría A según la FIAPF 2011

\begin{tabular}{|c|c|}
\hline Festival & $\begin{array}{l}\text { Lugar de } \\
\text { celebración }\end{array}$ \\
\hline $\begin{array}{c}\text { Festival Internacional de Cine de Berlín / Berlinale - } \\
\text { Berlin International Film Festival }\end{array}$ & Berlín (Alemania) \\
\hline $\begin{array}{c}\text { Festival Internacional de Cine de Cannes / Festival } \\
\text { de } \\
\text { Cannes }\end{array}$ & Cannes (Francia) \\
\hline $\begin{array}{c}\text { Festival Internacional de Cine de Shanghai / SIFF } \\
\text { Shanghai International Film Festival }\end{array}$ & Shanghai (China) \\
\hline $\begin{array}{c}\text { Festival Internacional de Cine de Moscú / MIFF } \\
\text { Moscow } \\
\text { International Film Festival }\end{array}$ & Moscú (Rusia) \\
\hline $\begin{array}{c}\text { Festival Internacional de Cine de Karlovy Vary / } \\
\text { KVIFF } \\
\text { Karlovy Vary International Film Festival }\end{array}$ & $\begin{array}{l}\text { Karlovy Vary } \\
\text { (Rep. Checa) }\end{array}$ \\
\hline $\begin{array}{c}\text { Festival Internacional de Cine de Locarno / Festival } \\
\text { del } \\
\text { Film Locarno }\end{array}$ & Locarno (Suíza) \\
\hline $\begin{array}{c}\text { Festival Internacional de Cine de Montreal / Festival } \\
\text { des } \\
\text { Films du Monde de Montréal. The World Film } \\
\text { Festival }\end{array}$ & Montreal (Canadá) \\
\hline $\begin{array}{c}\text { Muestra Internacional de Cine de Venecia / La } \\
\text { Biennale di } \\
\text { Venezia }\end{array}$ & Venecia (Italia) \\
\hline $\begin{array}{l}\text { Festival Internacional de Cine de San Sebastián / San } \\
\text { Sebastian International Film Festival }\end{array}$ & $\begin{array}{l}\text { San Sebastián } \\
\text { (España) }\end{array}$ \\
\hline $\begin{array}{c}\text { Festival Internacional de Cine de Varsovia / Warsaw } \\
\text { Film } \\
\text { Festival }\end{array}$ & Varsovia (Polonia) \\
\hline $\begin{array}{c}\text { Festival Internacional de Cine de Tokio / TIFF } \\
\text { Tokyo } \\
\text { International Film Festival }\end{array}$ & Tokio (Japón) \\
\hline $\begin{array}{c}\text { Festival Internacional de Cine de Mar del Plata / } \\
\text { Mar del } \\
\text { Plata International Film Festival }\end{array}$ & $\begin{array}{l}\text { Mar del Plata } \\
\text { (Argentina) }\end{array}$ \\
\hline $\begin{array}{c}\text { Festival Internacional de Cine de la India, Goa / IFFI } \\
\text { International Film Festival of India, Go }\end{array}$ & Goa (India) \\
\hline
\end{tabular}




\begin{tabular}{|c|c|}
\hline $\begin{array}{c}\text { Festival Internacional de Cine de El Cairo / Cairo } \\
\text { International Film Festiva }\end{array}$ & El Cairo (Egipto) \\
\hline
\end{tabular}

Fuente: Elaboración propia a partir del Ministerio de Cultura (2011)

Dentro de los 14 festivales pertenecientes a la categoría A, aparece un festival celebrado en territorio español: el Festival Internacional de Cine de San Sebastián, lo que supone para España una gran campaña comunicativa a nivel internacional. Se trata del festival más antiguo y más representativo del panorama nacional, celebrándose en 2011 su 59 edición. A partir de ahí, ha proliferado la aparición de dichos eventos, desde los más antiguos como el de Gijón o Sitges (con 49 y 45 ediciones respectivamente), a los de creación más reciente, que sólo en la década de 2000 a 2010 han sido más de 30; emergiendo con temáticas más específicas o para segmentos determinados, como el cine invisible, cine gay y lésbico, cine erótico o cine de terror (Tabla 3 y Figura 1).

Tabla 3. Festivales de cine más representativos de España

\begin{tabular}{|c|c|c|c|}
\hline Festival & $\begin{array}{c}\text { Lugar } \\
\text { celebración }\end{array}$ & Antigüedad & Edición \\
\hline Festival de Cine de San Sebastián & $\begin{array}{c}\text { San } \\
\text { Sebastián }\end{array}$ & 1953 & $59^{a}$ \\
\hline Festival de Cine de Gijón & Gijón & 1963 & $49^{a}$ \\
\hline Festival de Cine de Sitges & $\begin{array}{c}\text { Sitges } \\
\text { (Barcelona) }\end{array}$ & 1967 & $45^{\mathrm{a}}$ \\
\hline $\begin{array}{l}\text { Muestra Cinematográfica del } \\
\underline{\text { Atlántico Alcances }}\end{array}$ & Cádiz & 1968 & $44^{\mathrm{a}}$ \\
\hline $\begin{array}{l}\text { Festival de Cine de Cartagena } \\
\text { (España) }\end{array}$ & $\begin{array}{l}\text { Cartagena } \\
\text { (Murcia) }\end{array}$ & 1972 & $40^{\mathrm{a}}$ \\
\hline Motion Graphics Review & Huesca & 1972 & $40^{\mathrm{a}}$ \\
\hline $\begin{array}{l}\text { Festival de Cine Iberoamericano de } \\
\underline{\text { Huelva }}\end{array}$ & Huelva & 1974 & $38^{\mathrm{a}}$ \\
\hline $\begin{array}{l}\text { Bienal Internacional de Cine } \\
\underline{\text { Científico }}\end{array}$ & $\begin{array}{l}\text { Ronda } \\
\text { (Málaga) }\end{array}$ & 1977 & $35^{\mathrm{a}}$ \\
\hline$\underline{\text { Mostra de València }}$ & Valencia & 1980 & $31^{\mathrm{a}}$ \\
\hline Cinema Jove & Valencia & 1986 & $26^{a}$ \\
\hline Muestra Internacional de Cine y & Pamplona & 1986 & 25 \\
\hline
\end{tabular}


Turismo cultural - Festival de cine - Destino turístico - Imagen del destino - San Sebastián

\begin{tabular}{|c|c|c|c|}
\hline \multicolumn{4}{|l|}{ Mujeres de Pamplona } \\
\hline $\begin{array}{l}\text { Semana de Cine de Medina del } \\
\underline{\text { Campo }}\end{array}$ & $\begin{array}{l}\text { Medina del } \\
\text { Campo } \\
\text { (Valladolid) }\end{array}$ & 1988 & $24^{\mathrm{a}}$ \\
\hline Semana Negra de Gijón & $\begin{array}{c}\text { Gijón } \\
\text { (Asturias) }\end{array}$ & 1988 & $24^{\mathrm{a}}$ \\
\hline Semana del Cine Español & Murcia & 1989 & $23^{a}$ \\
\hline $\begin{array}{l}\text { Festival de cine fantástico de } \\
\underline{\text { Málaga }}\end{array}$ & Málaga & 1990 & $21^{a}$ \\
\hline Actual (festival) & Logroño & 1991 & $21^{\mathrm{a}}$ \\
\hline $\begin{array}{l}\text { Semana del Cine Experimental de } \\
\underline{\text { Madrid }}\end{array}$ & Madrid & 1991 & $21^{\mathrm{a}}$ \\
\hline $\begin{array}{l}\text { Mostra Internacional de Films de } \\
\text { Dones de Barcelona }\end{array}$ & Barcelona & 1993 & $19^{\mathrm{a}}$ \\
\hline L'Alternativa & Barcelona & 1993 & $19^{\mathrm{a}}$ \\
\hline Cinemad & Madrid & 1994 & $18^{\mathrm{a}}$ \\
\hline $\begin{array}{l}\text { Festival Solidario de Cine Español } \\
\underline{\text { de Cáceres }}\end{array}$ & Cáceres & 1994 & $18^{a}$ \\
\hline $\begin{array}{l}\text { Muestra de Cine Latinoamericano } \\
\underline{\text { de Cataluña }}\end{array}$ & Lérida & 1995 & $17^{\mathrm{a}}$ \\
\hline$\underline{\text { LesGaiCineMad }}$ & Madrid & 1995 & $17^{\mathrm{a}}$ \\
\hline $\begin{array}{l}\text { Festival de cine internacional de } \\
\underline{\text { Orense }}\end{array}$ & Ourense & 1996 & $16^{\mathrm{a}}$ \\
\hline $\begin{array}{l}\text { Primavera Cinematográfica de } \\
\text { Lorca }\end{array}$ & $\begin{array}{c}\text { Lorga } \\
\text { (Murcia) }\end{array}$ & 1996 & $16^{\mathrm{a}}$ \\
\hline $\begin{array}{l}\text { Festival de Cine Asiático de } \\
\underline{\text { Barcelona }}\end{array}$ & Barcelona & 1998 & $14^{\mathrm{a}}$ \\
\hline $\begin{array}{l}\text { Festival Internacional de } \\
\text { Cortometrajes y Cine Alternativo de } \\
\underline{\text { Benalmádena }}\end{array}$ & $\begin{array}{l}\text { Benalmádena } \\
\text { (Málaga) }\end{array}$ & 1998 & $14^{\mathrm{a}}$ \\
\hline Curt Ficcions & Barcelona & 1998 & $14^{\mathrm{a}}$ \\
\hline
\end{tabular}




\begin{tabular}{|c|c|c|c|}
\hline $\begin{array}{l}\text { Festival Internacional de } \\
\text { Cortometrajes La Boca del Lobo }\end{array}$ & Madrid & 1998 & $14^{\mathrm{a}}$ \\
\hline $\begin{array}{l}\text { Festival Internacional de Cine } \\
\text { Independiente de Elche }\end{array}$ & $\begin{array}{c}\text { Elche } \\
\text { (Alicante) }\end{array}$ & 1998 & $14^{\mathrm{a}}$ \\
\hline Sonorama & $\begin{array}{l}\text { Aranda del } \\
\text { Duero } \\
\text { (Burgos) }\end{array}$ & 1998 & $14^{\mathrm{a}}$ \\
\hline Festival de Cine de Pamplona & Pamplona & 1999 & $13^{\mathrm{a}}$ \\
\hline $\begin{array}{l}\text { Semana Internacional de Cine } \\
\text { Fantástico y de Terror de Estepona }\end{array}$ & $\begin{array}{l}\text { Estepona } \\
\text { (Málaga) }\end{array}$ & 1999 & $13^{\mathrm{a}}$ \\
\hline $\begin{array}{l}\text { Festival Internacional de Cine } \\
\text { Negro de Manresa }\end{array}$ & $\begin{array}{l}\text { Manresa } \\
\text { (Barcelona) }\end{array}$ & 1999 & $13^{\mathrm{a}}$ \\
\hline $\begin{array}{l}\text { Mecal. Festival de Cortometrajes de } \\
\text { Barcelona }\end{array}$ & Barcelona & 1999 & $13^{\mathrm{a}}$ \\
\hline Animadrid & $\begin{array}{l}\text { Pozuelo de } \\
\text { Alarcón } \\
\text { (Madrid) }\end{array}$ & 2000 & $12^{\mathrm{a}}$ \\
\hline $\begin{array}{l}\text { Festival Internacional de } \\
\text { Cortometrajes Ciudad de } \\
\text { Torrelavega }\end{array}$ & Santander & 2000 & $12^{\mathrm{a}}$ \\
\hline $\begin{array}{l}\text { Festival Internacional de Cine de } \\
\text { Las Palmas de Gran Canaria }\end{array}$ & $\begin{array}{c}\text { Las Palmas } \\
\text { de Gran } \\
\text { Canaria }\end{array}$ & 2000 & $12^{\mathrm{a}}$ \\
\hline $\begin{array}{l}\text { Festival de Cine Fantástico y Terror } \\
\underline{\text { de Las Palmas de Gran Canaria }}\end{array}$ & $\begin{array}{l}\text { Palmas de } \\
\text { Gran Canaria }\end{array}$ & 2000 & $12^{\mathrm{a}}$ \\
\hline Festival de cortometrajes Sonorama & $\begin{array}{c}\text { Aranda del } \\
\text { Duero } \\
\text { (Burgos) }\end{array}$ & 2000 & $12^{\mathrm{a}}$ \\
\hline Festival de Cine de Islantilla & $\begin{array}{l}\text { Islantilla } \\
\text { (Huelva) }\end{array}$ & 2000 & $12^{\mathrm{a}}$ \\
\hline Festival de Cortometrajes de Jerez & $\begin{array}{c}\text { Jerez de la } \\
\text { Frontera } \\
\text { (Cádiz) }\end{array}$ & 2000 & $12^{\mathrm{a}}$ \\
\hline$\underline{\text { Notodofilmfest }}$ & Madrid & 2001 & $11^{\mathrm{a}}$ \\
\hline
\end{tabular}


Turismo cultural - Festival de cine - Destino turístico - Imagen del destino - San Sebastián

\begin{tabular}{|c|c|c|c|}
\hline $\begin{array}{l}\text { Muestra de Cine Inédito Español de } \\
\text { Jaén }\end{array}$ & Jaén & 2001 & $11^{\mathrm{a}}$ \\
\hline $\begin{array}{l}\text { Festival Internacional de Cine } \\
\text { Arqueológico del Bidasoa }\end{array}$ & $\begin{array}{c}\text { Irún } \\
\text { (Guipúzcoa) }\end{array}$ & 2001 & $11^{\mathrm{a}}$ \\
\hline $\begin{array}{l}\text { Festival Internacional de } \\
\text { Cortometrajes Almería en Corto }\end{array}$ & Almería & 2002 & $10^{\mathrm{a}}$ \\
\hline $\begin{array}{l}\text { Festival de Cine Fantástico de } \\
\text { Bilbao }\end{array}$ & Bilbao & 2002 & $10^{\mathrm{a}}$ \\
\hline Festivalito & La Palma & 2002 & $10^{\mathrm{a}}$ \\
\hline $\begin{array}{l}\text { Festival Internacional de Cine Euro- } \\
\text { Árabe AMAL }\end{array}$ & $\begin{array}{l}\text { Santiago de } \\
\text { Compostela }\end{array}$ & 2003 & $9^{a}$ \\
\hline Festival de Cine Africano de Tarifa & $\begin{array}{l}\text { Tarifa } \\
\text { (Cádiz) }\end{array}$ & 2003 & $9^{a}$ \\
\hline $\begin{array}{l}\text { Festival de Cine de Animación de } \\
\text { Animación de Basauri }\end{array}$ & $\begin{array}{c}\text { Basauri } \\
\text { (Vizcaya) }\end{array}$ & 2004 & $8^{\mathrm{a}}$ \\
\hline Festival de Cine de Alicante & Alicante & 2004 & $8^{\mathrm{a}}$ \\
\hline DocumentaMadrid & Madrid & 2004 & $8^{\mathrm{a}}$ \\
\hline $\begin{array}{l}\text { Muestra de cine andaluz y del } \\
\text { Mediterráneo }\end{array}$ & $\begin{array}{l}\text { Archidona } \\
\text { (Málaga) }\end{array}$ & 2004 & $8^{\mathrm{a}}$ \\
\hline Curtocircuito & $\begin{array}{l}\text { Santiago de } \\
\text { Compostela }\end{array}$ & 2004 & $8^{\mathrm{a}}$ \\
\hline Festival de Cans & $\begin{array}{c}\text { Cans } \\
\text { (Pontevedra) }\end{array}$ & 2004 & $8^{a}$ \\
\hline Ciclo de Cine Argencine & $\begin{array}{c}\text { Madrid- } \\
\text { Buenos Aires }\end{array}$ & 2005 & $7^{\mathrm{a}}$ \\
\hline Festival Erótico de Madrid & Madrid & 2005 & $7^{\mathrm{a}}$ \\
\hline Festival Punto de Vista & Pamplona & 2005 & $7^{\mathrm{a}}$ \\
\hline Fotogramas en Corto & $\begin{array}{c}\text { Revista } \\
\text { Fotogramas }\end{array}$ & 2005 & $7^{a}$ \\
\hline $\begin{array}{l}\text { Festival Internacional de Cine } \\
\text { Documental de Navarra }\end{array}$ & Navarra & 2005 & $7^{a}$ \\
\hline Festival de cine Gay y Lésbico de & $\begin{array}{c}\text { Las Palmas } \\
\text { de Gran }\end{array}$ & 2006 & $6^{\mathrm{a}}$ \\
\hline
\end{tabular}




\begin{tabular}{|l|c|c|c|}
\hline$\underline{\text { Canarias }}$ & Canaria & \\
\hline$\underline{\text { Festival de Cine Lésbico y Gai de }}$ & $\begin{array}{c}\text { Sevilla- } \\
\text { Huelva- } \\
\text { Málaga }\end{array}$ & 2006 & $6^{\mathrm{a}}$ \\
\hline$\underline{\text { Festival Internacional de Cine de }}$ & $\begin{array}{c}\text { Marbella } \\
\text { (Málaga) }\end{array}$ & 2006 & $6^{\mathrm{a}}$ \\
\hline$\underline{\text { Festival Internacional de Cine de }}$ & Ibiza & 2007 & $5^{\mathrm{a}}$ \\
\hline$\underline{\text { Ibiza }}$ & Granada & 2007 & $5^{\mathrm{a}}$ \\
\hline$\underline{\text { Festival La Cabina }}$ & Valencia & 2008 & $4^{\mathrm{a}}$ \\
\hline$\underline{\text { Festival de cortometrajes }}$ & Madrid & 2008 & $4^{\mathrm{a}}$ \\
\hline$\underline{\text { Cortogenia }}$ & Sevilla & 2009 & $3^{\mathrm{a}}$ \\
\hline$\underline{\text { Festival de Cine Europeo de Sevilla }}$ & Bilbao & 2009 & $3^{\mathrm{a}}$ \\
\hline$\underline{\text { Festival Internacional de Cine }}$ & & & \\
\hline$\underline{\text { Invisible de Bilbao }}$ & & & \\
\hline
\end{tabular}

Fuente: Elaboración propia a partir del Ministerio de Cultura (2011)

Figura 1. Festivales de cine en España 1953-2009

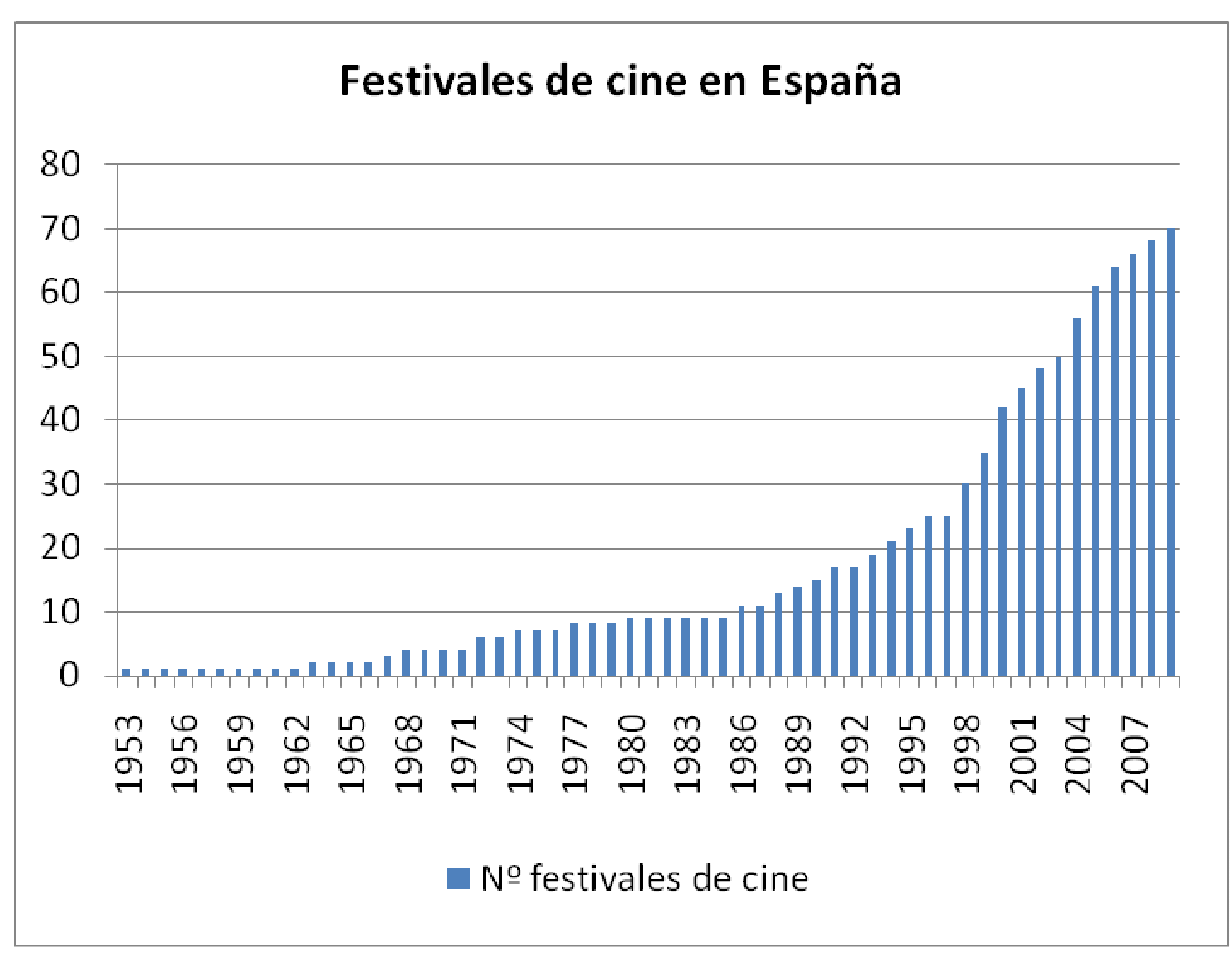

Fuente: Elaboración propia a partir del Ministerio de Cultura (2011) 


\section{EL FESTIVAL DE CINE DE SAN SEBASTIÁN, EL FESTIVAL MÁS INTERNACIONAL DE ESPAÑA}

El Festival de Cine de San Sebastián es el pionero en España, con 59 años de trayectoria. Los premios otorgados durante el mismo son numerosos y de notables cuantías, desde la conocida Concha de Oro a premios financiados por patrocinadores, como el de la Kutxa-Nuevos directores (90.000 euros), Premio Horizontes (AECID) a largometrajes producidos total o parcialmente en América Latina, de 35.000 euros, o el Premio Serbitzu Zinemira, de 20.000 euros (web oficial del festival, 59 edición).

El turismo cinematográfico, definido como "la actividad de ocio ligada a localizaciones geográficas relacionadas con el cine" (Rodríguez y Fraiz, 2010), incluye como parte de sus atractivos las localizaciones de rodajes, ciudades con grandes estudios cinematográficos o incluso poblaciones ligadas a la vida de actores, directores o productores (Rodríguez y Fraiz, 2010, p. 2). De un modo altamente vinculado con dicha definición, el Festival de Cine de San Sebastián consigue atraer la atención de numerosos turistas con la presencia de actores/actrices, directores y productores de reconocida fama mundial. En sus últimas ediciones, se han dejado ver en el festival actores y actrices con Glenn Close, Julia Roberts, Meryl Streep, Richard Gere o Antonio Banderas. Tal evento repercute por tanto de forma directa en el sector turístico, así como en el comercio, transporte y otros servicios de la ciudad.

Según un estudio de SAVIA (2006), la celebración de festivales de cine incrementa en un $85 \%$ la ocupación hotelera de la ciudad donde se celebra. Un estudio realizado por la consultora vasca IKEI (2006), refleja también que el 31\% de los turistas que acuden a actividades culturales necesitan alojamiento, su estancia media es de 3,5 días y el $88 \%$ de los que pernoctan lo hacen en la misma ciudad.

Aparte de los turistas atraídos por el festival, se añade a la cifra de visitantes de la ciudad, los cinéfilos y periodistas, llegando en 2006 (edición 54 del festival) a un total de 3.000. El año anterior, 2005, se acreditaron 1.104 personas de 679 empresas y 45 países (SAVIA, 2006), convirtiéndose a su vez en un evento de carácter promocional para el país, dándose así a conocer España al resto del mundo.

En la propia página web del festival, se facilita información que puede resultar interesante para el turista, como las localizaciones del evento, puntos de interés, cines, transportes y hoteles. En la propia web son 10 los hoteles referenciados, desde el Hotel María Cristina, de la cadena Starwood y 5 estrellas, a hoteles de menor categoría, entre 4 y 2 estrellas (Figura 2). A través de un link se puede acceder a la web del Ayuntamiento de San Sebastián y descubrir más hoteles y otro tipo de alojamientos (pensiones o casas rurales, entre otros). 
Figura 2. Información de interés para el turista que acude al Festival de San Sebastián

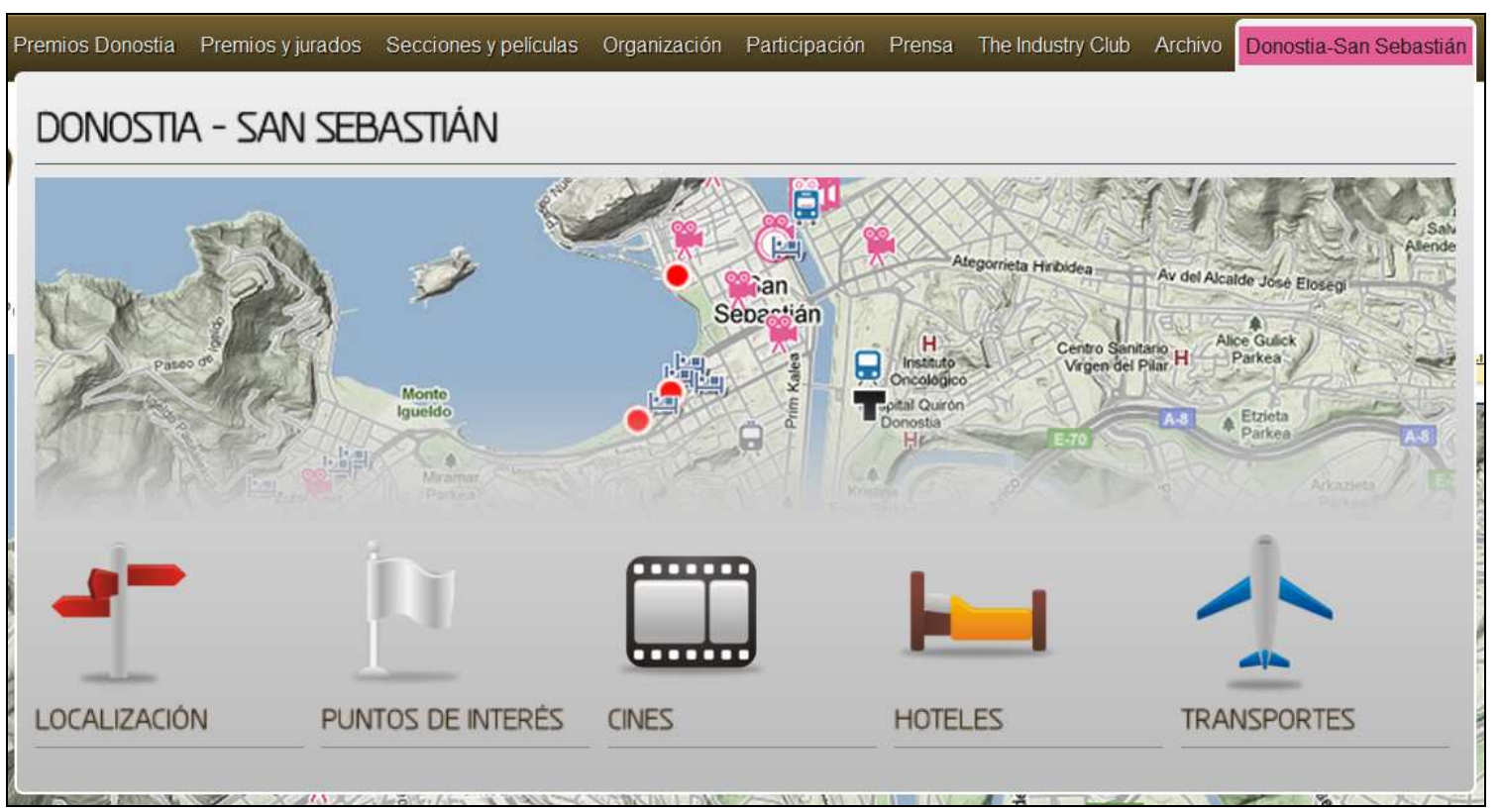

Fuente: http://www.sansebastianfestival.com (2011)

En lo que respecta al nivel de ocupación hotelera, datos de la última edición (59), muestran porcentajes próximos al 100\%. Así, en 2011, el portal web trivago asegura una ocupación del 99\% durante la celebración del primer fin de semana del festival (16-18 de septiembre), quedando habitaciones libres en tan sólo 12 de los 128 hoteles analizados.

\subsection{El producto turístico vinculado al festival de cine de San Sebastián.}

Según la Tabla 2, en la que se analizan los festivales de categoría A, a nivel de Europa, los de mayor relevancia y repercusión son Berlín, Venecia y Cannes, junto el de San Sebastián.

Partiendo de esta premisa se realiza un estudio para observar si existen productos turísticos asociados al festival, y por el tanto, elementos que potencian el sector turístico para ese destino.

Dada la amplitud y variedad de información disponible en la red sobre dichos eventos, se toma como referencia la web de turismo oficial de las ciudades sede de los festivales y se analiza la información existente sobre los festivales y su vinculación a la mejora del destino como enclave turístico. En la única web oficial de turismo que encontramos un producto turístico vinculado al festival es la de Donostia-San Sebastián Turismo (www.sansebastianturismo.com).

El paquete ofertado para el festival de cine de San Sebastián presenta 4 variantes que se recogen en la siguiente tabla (Tabla 4 ). 
Tabla 4. Características del paquete turístico del festival de cine de San Sebastián

\begin{tabular}{|c|c|c|}
\hline $\begin{array}{c}\text { TIPO } \\
\text { PAQUETE }\end{array}$ & PRECIO & CARACTERÍSTICAS \\
\hline $\begin{array}{l}\text { Pack } \\
\text { Inauguración } \\
\text { Kursaal }\end{array}$ & $\begin{array}{l}\text { Desde } \\
127,40 € \text { por } \\
\text { persona }\end{array}$ & $\begin{array}{l}\text { Alojamiento con café da mañana } \\
\text { Programa festival } \\
\text { Visita guiada "San Sebastián de Cine" } \\
\text { Welcome bag con material turístico de la } \\
\text { ciudad } \\
\text { Entrada Gala Inaugural }\end{array}$ \\
\hline $\begin{array}{l}\text { Pack Clausura } \\
\text { Kursaal }\end{array}$ & $\begin{array}{l}\text { Desde } 113 € \\
\text { por persona }\end{array}$ & $\begin{array}{l}\text { Alojamiento con café da mañana } \\
\text { Programa festival } \\
\text { Visita guiada “San Sebastián de Cine" } \\
\text { Welcome bag co material turístico de la } \\
\text { ciudad } \\
\text { Entrada Gala Clausura Kursal }\end{array}$ \\
\hline $\begin{array}{l}\text { Pack Clausura } \\
\text { Anoeta }\end{array}$ & $\begin{array}{l}\text { Desde } 66 € \\
\text { por persona }\end{array}$ & $\begin{array}{l}\text { Alojamiento con café da mañana } \\
\text { Programa festival } \\
\text { Visita guiada "San Sebastián de Cine" } \\
\text { Welcome bag con material turístico de la } \\
\text { ciudad } \\
\text { Entrada Gala Clausura Anoeta }\end{array}$ \\
\hline $\begin{array}{l}\text { Pack "Sesión } \\
\text { Continua" }\end{array}$ & $\begin{array}{l}106 € \quad \text { por } \\
\text { persona }\end{array}$ & $\begin{array}{l}\text { Alojamiento con café da mañana } \\
\text { Programa festival } \\
\text { Visita guiada "San Sebastián de Cine" } \\
\text { Welcome bag con material turístico de la } \\
\text { ciudad } \\
\text { Entrada } 2 \text { pases por día }\end{array}$ \\
\hline
\end{tabular}

Fuente: elaboración propia a partir de www.sansebastianturismo.com

Después, el propio turista podrá combinar el paquete con el hotel que le guste, desde 1 a 4 estrellas, variando el precio del paquete según la elección. Una de las cosas más interesantes es la posibilidad de elaborarlo según las necesidades, tanto por días o evento a visitar en el festival, como en el propio diseño del paquete que va enfocado a diferentes tipos de usuarios según rango económico. Además, destaca que todos ellos se complementaran con visitas la ciudad lo que potencia su conocimiento, difusión y fortalecimiento en la mente de turista, posibilitando conocer otros recursos y atractivos turísticos. Se trabaja en una estrategia de fidelización, mediante el cine que agrupa al resto de componentes como: gastronomía, cultura, patrimonio, naturaleza.... 
Tabla 5. Combinaciones de paquetes según hoteles

\begin{tabular}{|c|c|c|c|c|c|c|c|}
\hline \multirow{3}{*}{$\begin{array}{l}\text { Hotel } \\
\text { escogido } \\
\text { Villa Soro } 4^{*}\end{array}$} & \multicolumn{3}{|c|}{ PAQUETE DE 1 NOCHE } & \multicolumn{4}{|c|}{ PAQUETE 2 NOCHES } \\
\hline & $\begin{array}{l}\text { Inaugura } \\
\text { ción } \\
\text { Kursaal }\end{array}$ & $\begin{array}{l}\text { Clausur } \\
\text { a } \\
\text { Kursaal }\end{array}$ & $\begin{array}{l}\text { Clausur } \\
\text { a } \\
\text { Anoeta }\end{array}$ & \multicolumn{2}{|c|}{$\begin{array}{l}\text { Sesión continua } \\
1^{\mathrm{o}} \text { y } 2^{\mathrm{o}} \text { día } \\
\text { e } 4^{\mathrm{o}}\end{array}$} & $\begin{array}{l}\text { Precio } \\
\text { noche } \\
\text { extra }\end{array}$ & $\begin{array}{l}\text { Suplemen } \\
\text { to } \\
\text { individua } \\
1\end{array}$ \\
\hline & 222.00 & 175.00 & 324.00 & 324.00 & 162.00 & 145.80 & \\
\hline $\begin{array}{l}\text { Silken } \\
\text { Amara } \\
\text { Plaza 4* }\end{array}$ & ---- & 150.00 & 103.00 & --- & 180.00 & 90.00 & 70.00 \\
\hline $\begin{array}{l}\text { Barceló } \\
\text { Costa Vasca } \\
4^{*}\end{array}$ & 155.50 & 165.50 & 118.50 & 211.00 & 211.00 & 105.50 & 90.00 \\
\hline $\begin{array}{ll}\text { Palacio } & \text { de } \\
\text { Aiete } 4^{*} & \end{array}$ & 156.92 & ---- & $\begin{array}{c}--- \\
-\cdots\end{array}$ & 213.84 & ---- & 106.92 & 48.60 \\
\hline Avenida $3^{*}$ & 127.40 & ---- & ---- & 154.80 & ---- & 77.40 & 65.90 \\
\hline $\begin{array}{ll}\text { La } & \text { Galeria } \\
2^{*} & \end{array}$ & ---- & 133.50 & 86.50 & $\begin{array}{c}--- \\
--1\end{array}$ & 147.00 & 73.50 & 42.50 \\
\hline $\begin{array}{l}\text { Monte Ulia } \\
1^{*}\end{array}$ & ---- & 113.00 & 66.00 & ---- & 106.00 & 53.00 & 20.00 \\
\hline
\end{tabular}

Fuente: Elaboración propia a partir de www.sansebastianturismo.com

\section{CONCLUSIONES}

El turismo cultural abarca una serie de actividades, que al igual que cualquier otra modalidad turística, intentan satisfacer las necesidades y anhelos de su consumidor, el turista. En este caso, tales deseos se satisfacen a través de culturas exóticas, arte, folclore, observación de ciertos edificios, pueblos o monumentos con cierto interés histórico, produciendo en el turista un conjunto de sensaciones intelectuales, emocionales y psicológicas (Stebbins, 1996: 948).

Evidencias de ello son las fotos y vídeos que demuestran el alto consumo de productos turístico-culturales que buscan recordarse destacando algún matiz diferenciador, convirtiéndose las mismas imágenes en un elemento altamente vinculado a este tipo de turismo, no sólo como interés de fijación en la memoria, sino como propio consumo del mismo. Las imágenes y sueños se convierten en una parte importante de este tipo 
de turismo, es más, el turismo en sí es una experiencia visual (Hellín y Martínez, 2009: 1).

Así, uniendo perspectivas como son la novedad a través de la comercialización de sensaciones -economía en la que estamos inmersos-, la experiencia visual que genera el turismo y más concretamente el turismo cultural y el turismo cultural como escenario propicio para el nacimiento de variedades turísticas susceptibles de generar emociones, surgen nuevas variantes turísticas. Entre ellas, se encuentra el turismo vinculado a la celebración de festivales de cine, que según el modelo de Acerenza (1991) formaría parte de las actividades lúdico-festivas.

Tal y como se ha justificado a lo largo del presente artículo, estamos ante un sector en alza. Sólo en España hemos pasado de tan sólo un festival de cine en 1953, a la celebración de aproximadamente 70 en la actualidad, cifra destacada teniendo en cuenta las características que éstos deben cumplir para seguir atrayendo al público:

- Novedad: deseo de buscar nuevas y diferentes.

- Socialización: necesidad de interactuar con un grupo.

- Prestigio/status: deseo de ocupar una alta posición.

- Descanso y relax: evadirse mental y físicamente de la rutina.

- Valores educacionales/enriquecimiento intelectual: deseo de ampliar los conocimientos intelectuales.

- Mejorar el parentesco y relaciones: deseo de mejorar las relaciones familiares.

- Regresión: deseo de participar en experiencias/comportamientos que nos recuerdan a la etapa de adolescente o niño.

No es fácil que un festival de cine mantenga a lo largo del tiempo todas estas características, las cuales son claves para sobrevivir, y aun así actualmente se celebran más de 45 festivales de cine en España que tienen más de 10 años de trayectoria.

Paralelamente a la supervivencia de los festivales de cine, destaca el desarrollo que el turismo ha tenido vinculado a dichos eventos. Podemos calificar el festival de cine como el atractivo principal para un turista cultural, pero como en toda actividad turística, la oferta complementaria se hace imprescindible. Así es que los destinos turísticos han sabido aprovechar la atracción que éstos generan, para ofertar y promocionar recursos turísticos del destino de celebración, llegando a crear paquetes turísticos que combinan la asistencia a distintas proyecciones del festival, acto de apertura o acto de clausura, alojamiento en la zona y visitas turísticas guiadas.

El ejemplo más representativo a nivel nacional es el del Festival de Cine de San Sebastián, festival más antiguo de España (desde 1953) y más internacional, de categoría A según la FIAPF (2011). Tras un análisis de contenido de su página web oficial, y la comparación con las páginas web oficiales de otros festivales de categoría A, como el de Berlín, Venecia o Cannes, se concluye con que es el que vincula de un modo más estrecho la celebración del propio festival y la ciudad en que se celebra, pasando a ser el turismo de San Sebastián un componente más del festival. 


\section{REFERENCIAS}

Acerenza, M. A. (1991). Administración del Turismo. Editorial Trillas. México.

Bonet, L. (2003). “Turismo Cultural: Una reflexión desde la ciencia económica". Portal Iberoamericano de Gestión Cultural (www.gestioncultural.org).

Craik, J. (1997). “The culture of tourism”. En Rojek, C. y Urry, J. Touring cultures. London: Routledge, 113-136.

Crompton, J. L. y McKay, S. L. (1997). "Motives of visitors attending festival events". En Annals of Tourism Research, vol. 24, n², 425-439.

García, A. y Alburqueque, F. J. (2003). “El turismo cultural y el de sol y playa: ¿sustitutivos o complementarios?". En Cuadernos de Turismo, nº 11, 100-101.

Gonzalo, P. (2006). "El turismo cultural de Festivales y Eventos como herramienta para la segmentación de la demanda turística". En Investigación y Marketing, n ${ }^{\circ}$ 87: 2530.

Inglehart, R. (1989). Culture Shift in Advanced Industrial Society. Princeton University Press.

Lee, T. y Crompton, J. L. (1992). "Measuring novelty seeking in tourism". En Annals of Tourism Research, vol. 19, nº4, 732-751.

Markwell, K. (2001). "An intimate rendezvous with nature? Mediating the touristnature experience at three tourist sites in Borneo". En Tourist Studies, nº. 1: 39-58.

Ministerio de Cultura (2011): Festivales y otras manifestaciones de cine y audiovisuales, online en http://www.mcu.es/cine/CE/Festivales/Festivales.html (consultado el 10/11/2011).

OMT (Organización Mundial del Turismo) (2005): Datos esenciales, edición 2004.

Reinstein, J. (2009). Tesis doctoral La proyección turística de la industria cinematográfica: estudios de cine Ciudad de la luz Alicante. Universidad de Alicante.

Richard, G. y Bonink, C. (1995). “European Cultural Tourism Markets”. En Journal of Vacation Marketing, Vol.1, 173-180.

Richards, G. (Ed.) (1996): Cultural tourism in Europe. Oxford: Wallingford.

Richards, G. (2004). “¿Nuevos caminos para el turismo cultural?” Association for Tourismand Leisure Educatio (ATLAS), Observatorio Interarts, Barcelona.

Rodríguez, L. y Fraiz, J.A. (2010). “Consideraciones estratégicas para la promoción del turismo en Galicia a través del cine". En Revista Galega de Economía, vol.19, n² 2, 1-11.

Santana, A. (2003). “Turismo cultural, culturas turísticas”. En Horizontes antropológicos, vol. $9, \mathrm{n}^{\circ} 20,1-12$. 
Savia (2006). "El impacto turístico del festival de cine de San Sebastián", SAVIA, 52-53.

Stebbings, R. A. (1996). "Cultural tourism as serious leisure". En Annals of Tourism Research, $\mathrm{n}^{\circ} .23,948-950$.

Villa, A. D. (2001): "El turismo cultural o la mercantilización de la cultura”, Congreso virtual de Turismo 2001, online en htpp:/ / www.naya.org.ar.

\section{Noelia Araújo Vila}

Licenciada en Administración y Dirección de Empresas y actualmente Doctoranda en Dirección y Planificación del Turismo. Colabora como profesora invitada en el Máster en Dirección y Planificación del Turismo de la Universidad de Vigo (desde el 2010) y en el Departamento de Organización de Empresas y Marketing de la misma Universidad (desde el año 2007), además de cooperar en diversos proyectos de investigación del ámbito empresarial y turístico.

\section{Trinidad Domínguez Vila}

Doctora en Gestión y Dirección de Empresas, Máster en Dirección y Planificación del Turismo y Profesora Ayudante Doctora del Departamento de Organización de Empresas y Marketing de la Universidad de Vigo. 